\title{
Profile of the GMC
}

\section{Discipline III: the final stages}

\author{
Richard Smith
}

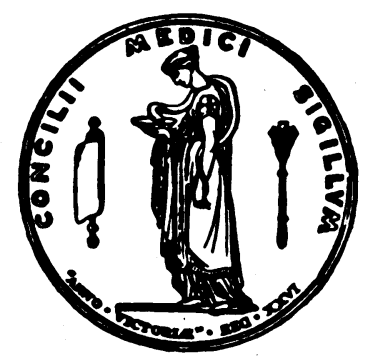

Less than $15 \%$ of the complaints made to the General Medical Council reach the preliminary screening committee. Yet this committee is the first stage in the disciplinary process when real power can be exercised over the offending doctor. The diversion of so many complaints worries critics of the GMC.' The council argues that so many cases are diverted because they do not raise a question of serious professional misconduct, but the American sociologist Rosenthal has argued that limited resources may be the real reason.'

\section{Work of the preliminary proceedings committee}

The preliminary proceedings committee was set up at the suggestion of the Merrison inquiry into the regulation of the medical profession and replaced the penal cases committee.' It has 11 members, two of whom are lay members, and meets three times a year. (The amount of time that must be spent sitting on this and other committees limits the number of doctors and lay people who could take on the work. It may be particularly difficult for junior doctors and women doctors with family responsibilities, explaining in part the domination of the GMC by elderly male doctors. The preliminary screener, the doctor who has decided which cases should be considered by this committee, is its chairman.

The committee meets in private, and the evidence is presented on paper. Each member of the committee receives a large package of papers beforehand and is expected to have read them. (One year the papers sent to members of the committee weighed almost $3.5 \mathrm{~kg}$.) This adds to the substantial workload. The committee sees the evidence of the complainant, the response from the doctor, and the results of any investigations that there might have been. Up to half of the cases that the committee considers are the result of convictions in the courts.

One of the powers of the committee is to suspend a doctor from the register pending a decision by the professional conduct committee. If this power is to be used the doctor will be asked to appear before the committee. This has happened on only two occasions since the power was given to the committee in 1978. It is used only in cases when the committee believes that the public are at risk if the doctor continues to practise while waiting to appear before the professional conduct committee.

The committee is assisted by a legal assessor, who is almost always a Queen's Counsel. The assessor does not take part in the judgment but advises on legal points. All of those I spoke to who had worked on the committee-including people critical of the GMCagreed that the committee takes its work very seriously and works hard; its members have read all the paperwork before they arrive, and the standard of the paperwork was said by all to be very good. The committee also seems - by legal standards - to work fast, although no data are available on how quickly cases flow through the system. Sometimes the preliminary proceedings committee will be judging complaints that have been made to the council only a few weeks before, but if the complaint required investigation and arrived at an awkward time (just after
London WC1H 9JR

Richard Smith, MB, senior assistant editor

Br.Med f 1989:298:1632-4

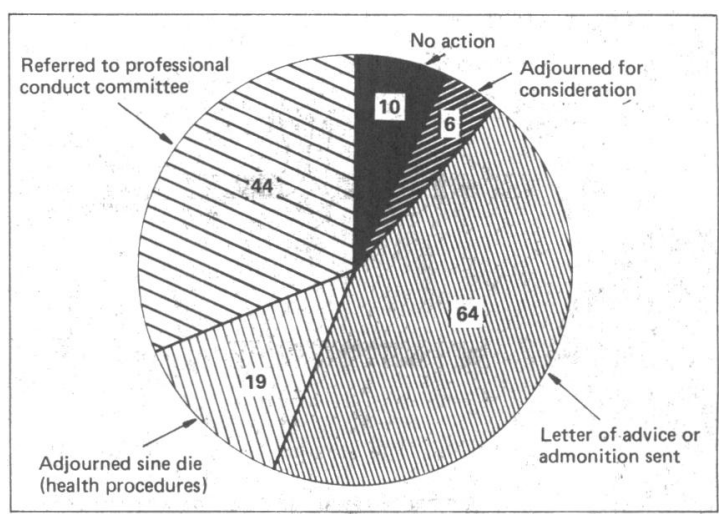

FIG 1 -Outcome of 143 cases considered by preliminary proceedings committee in 1988

one of the meetings) it might take many months to reach the committee.

If the committee thinks that a doctor may have been guilty of serious professional misconduct and that there is enough evidence to support the charge the case will be forwarded to the professional conduct committee. Alternatively, the committee might dismiss the case; another option is to refer the case to the health committee if it decides that the doctor's offence is rooted in a health problem, or it might adjourn the case and seek further evidence on the doctor's fitness to practise. The final option would be to send the doctor a warning letter. Figure 1 shows the outcome of 143 cases concerning 127 doctors considered by the committee in 1988. ${ }^{+}$The committee does not work by consensus: votes are taken, and if the committee is equally split the chairman has an additional casting vote.

Because the committee meets in private detailed firsthand accounts of its work are rare. Jean Robinson, a lay member of the committee, has, however, given her impressions of its work:

Most of the cases we were looking at were doctors who had already been punished elsewhere [by the courts or service committee hearings]

We saw virtually no cases concerning medical care by hospital doctors. In six years I can remember seeing only one such case from a member of the public. Almost all "medical" cases were the GP cases forwarded by the DHSS.

Apart from "sex" or "confidentiality" cases almost none ... came from members of the public. People who wrote directly to the GMC because they thought a doctor's standard of practice was dangerous were probably wasting their time.'

Again, because the committee meets in private and only skeletal data are produced it is impossible to verify many of Mrs Robinson's points. (But some data are available. The preliminary proceedings committee considered 26 cases of neglect of responsibilities to patients last year: 23 cases concerned NHS general practitioners, one concerned an NHS hospital doctor, and two concerned private doctors - one a general practitioner and one a hospital doctor.) That many of Mrs Robinson's statements cannot be verified may speak volumes in itself, and among those members of the public who encounter the GMC-for instance, members of community health councils and various patients' organisations-there is a distrust of it. 
The council has arguments to counter these anxieties, but the distrust is important in itself. It is not enough to serve the public interest: the council must be seen to do so. Many doctors who are members of the preliminary proceedings committee and other lay members do not share Mrs Robinson's doubts about the committee: they think that it does a difficult job well.

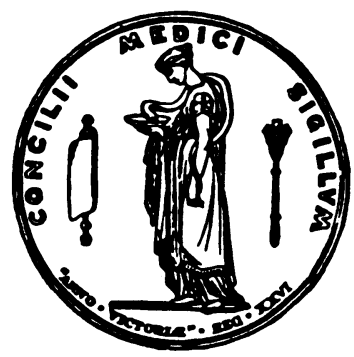

\section{The professional conduct committee}

The professional conduct committee is the GMC committee that is known to the public, which reads of salacious cases of doctors accused of having sexual relationships with their patients and hears of some of the most outstanding cases of professional neglect. And it was the forerunner of this committee that appeared in A J Cronin's The Citadel and heard the case of Bodkin Adams, the Eastbourne doctor accused in court of murdering an elderly woman patient. The committee meets in public, and its meetings have all the drama of a court hearing. In a grand room with portraits of former presidents on the walls the accused doctor sits with his or her lawyer before a panel of judges. The chairman of the committee, often the president of the GMC, sits in the middle, and the legal assessor and some council staff sit about him. The press, meanwhile, sit up in the gallery, waiting for something "juicy." Cases are commonly reported only if they contain something of such interest; routine neglect is boring.

Thirty two members of the council, six of them lay members, are elected to the professional conduct committee. The committee sits three times a year for up to four weeks with two panels of 11 members (two of them lay members) invited to sit for two weekly periods; six members constitute a quorum. The chairmen are chosen by the president, and the full committee never meets. The members are elected each year, but the voting system ensures that there is some continuity. The committee tends to meet for more days each year-not so much because the number of cases is increasing but more because cases are taking longer, seemingly because they are becoming more legalistic. Complainants are not eligible for legal aid, but they are usually represented by the council's solicitors at the council's expense. The committee has a legal assessor to advise it on points of law.

Unlike the members of the preliminary proceedings committee the members of the professional conduct committee have no papers before them except the charges against the doctors. The case against the doctor is presented by the council or the complainant's solicitors or counsel, and witnesses - both expert witnesses and witnesses to the facts--may be called. These witnesses may be cross examined by the doctor's lawyers, who will then mount a defence, calling witnesses as necessary, who may also be cross examined.

The committee first decides whether the facts are proved, retiring to do this. If the committee does so it must decide whether the facts amount to serious professional misconduct. Before it decides this the complainant's lawyers present evidence on the doctor's character and history and the extent to which the facts indicate serious professional misconduct. The doctor's lawyers may present mitigating evidence on their client's character and (if relevant) the usual standard of his practice. This makes embarrassing listening, and Nigel Spearing, the member of parliament who is campaigning for the GMC to introduce a lesser charge in addition to serious professional misconduct, thinks that this is unjust. "If a driver is found to have been guilty of dangerous driving you don't listen to a lot of evidence on what a good driver he is most of the time and then find him not guilty." But the professional conduct committee does listen to this evidence, and it may influence its judgment on whether the doctor is guilty of serious professional misconduct and on what sentence it passes. In this way serious professional misconduct is less like a criminal charge and more a judgment of behaviour over time. There is a difference between an error in a career when there is abundant evidence of a good and steady standard of care for patients and an error plus a history of complaints of the same sort of behaviour from which the doctor seems to have learnt nothing.

The committee may find that the doctor is not guilty of serious professional misconduct: this is what happened in the cases of 11 of the 40 doctors that it judged in $1988 .^{+}$Even if the doctor is found guilty of serious professional misconduct he or she may simply be admonished; this is what happened to six doctors in 1988. The committee has the power to make registration conditional-on, for instance, restricting prescribing or the range of practice, or taking further training - and this power was used in the cases of two doctors in 1988. The committee may refer a doctor to the health committee, and it referred one such doctor in 1988. Fjnally, it may suspend the doctor from the register for up to 12 months (11 doctors in 1988) or erase him or her from it (six doctors in 1988). Doctors who have been erased from the register may apply for reinstatement after 10 months, and these applications are heard by the professional conduct committee, which heard 15 such cases in 1988 (the most ever), and reinstated three doctors.

\section{Appeals}

Appeals against the decisions of the professional conduct committee may be made by doctors to the judicial committee of the Privy Council within 28 days afterwards. (Complainants cannot appeal to the Privy Council but may appeal to the High Court on a point of law.) The number of appeals is increasing: there were only 11 in the whole of the 1960s, but there have already been 33 in the 1980 s. Few of these appeals are successful, and none have succeeded in overturning the committee's decision whether a doctor has been guilty of serious professional misconduct - because the Privy Council considers that this is a professional judgment.

Another way of disputing the disciplinary processes of the GMC is to apply for judicial review, and this has happened twice.

\section{Lack of feedback}

One criticism of the GMC is that it does not use all the information it gathers on what is wrong with medical practice in Britain to provide any systematic feedback.' Some cases are reported in the press, and some data are presented in the council's annual report together with some general advice-on, for instance, the importance of communicating well with patients and avoiding becoming easy prey for drug addicts. But few doctors read the annual report of the GMC.

In Sweden, by contrast, the private insurance system that operates the country's no fault system of compensating medical injuries and the Medical Responsibility Board, which deals with patients' complaints, between them make considerable use of the data they generate.' The no fault fund has collected data on all patient injuries and published them, and it has conducted studies on high risk procedures. Regular reports are published in the journal of the Swedish Medical Association, and reports on settled claims are sent back to the institution where the injury arose. The Medical Responsibility Board used to publish reports on its cases in the medical association's journal, but now produces its own 10 times a year - the 
GMC might well look at more imaginative and helpful ways of using its data and reports.

\section{General anxieties about the disciplinary processes}

Many of the worries about the GMC's disciplinary system focus on the process, and these have been described in this article and the last two articles $(3$ June, p 1502, and 10 June, p 1569) and explored by Jean Robinson.' But other anxieties have arisen from looking at the outcome of the system, as recorded by Rosenthal.

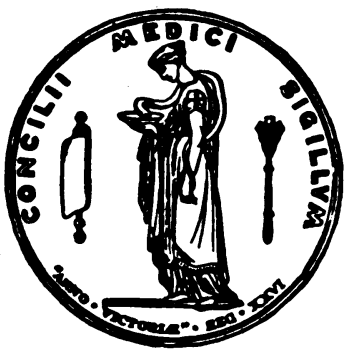

Firstly, Rosenthal looked at the numbers of doctors with non-European names appearing before the disciplinary committees (the disciplinary committee and penal affairs committee before 1980 and the preliminary proceedings committee and professional conduct committee since) and noted that they featured in $45 \%$ of cases in the 'seventies when non-European doctors made up about a third of all doctors. ${ }^{2}$ Interpreting these data is difficult - not least because names do not necessarily correlate with ethnic group. But without better data they are worth considering and might be held to mean that the council is biased against doctors from ethnic minorities or that doctors with nonEuropean names are more likely to commit offences that might amount to serious professional misconduct.

Rosenthal's second point is that the number of cases reviewed by the disciplinary committees has remained fairly static whereas the number of doctors has increased enormously (fig 2). She argues that this restriction is imposed by the resources of the GMC.

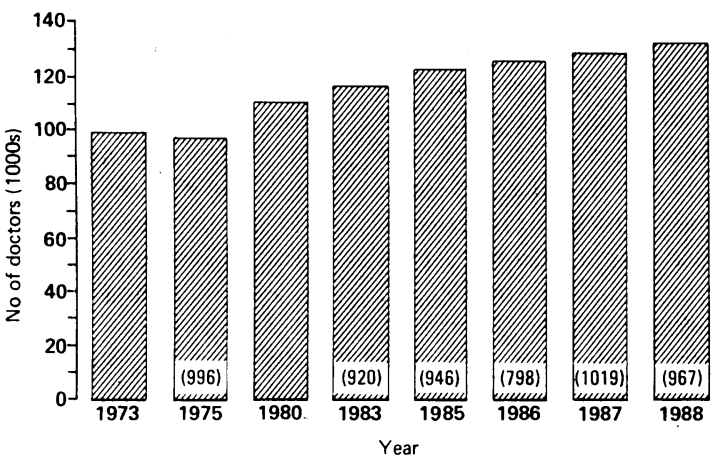

The council does not accept this. Rosenthal is not, I think, arguing that the council consciously rejects cases because of resource limitations but rather that the machinery operates to keep cases down: "The number of cases actually reviewed ... is a function of limited time, limited personnel, and limited facilities." She argues that "there is a striking relationship between size of staff and number of cases taken on"-and produces data to support this statement. "Therefore," she writes, "its functions are symbolic, signalling to

FIG 3-Rate of complaints to two regional health authorities, 1977-87 (reproduced with permission of the King's Fund Institute)

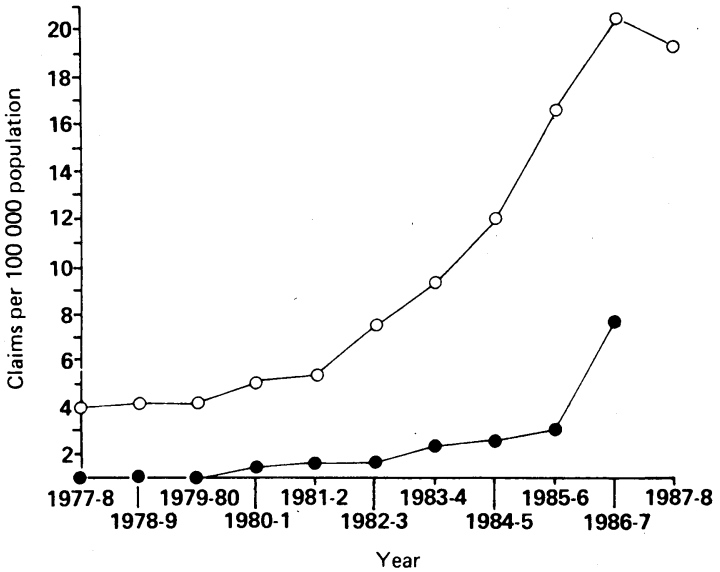

Numbers of complaints to General Medical Council, cases heard by disciplinary committees, and suspensions and erasures during $1973-88^{\star}$

\begin{tabular}{|c|c|c|c|c|c|}
\hline Year & Doctors & Complaints & $\begin{array}{c}\text { Cases } \\
\text { considered } \\
\text { by } \\
\text { disciplinary } \\
\text { committees } \dagger\end{array}$ & $\begin{array}{l}\text { Erasures or } \\
\text { suspensions }\end{array}$ & $\begin{array}{c}\% \text { Erasures } \\
\text { or } \\
\text { suspensions }\end{array}$ \\
\hline 1973 & 99593 & & 120 & 12 & 0.00012 \\
\hline 1975 & 98144 & 996 & 155 & 29 & 0.00029 \\
\hline 1980 & 110851 & & 113 & 15 & 0.00014 \\
\hline 1983 & 117219 & 920 & 143 & 19 & $0 \cdot 00016$ \\
\hline 1985 & 123066 & 946 & 146 & 21 & $0 \cdot 00017$ \\
\hline 1986 & 126448 & 798 & 167 & 18 & 0.00014 \\
\hline 1987 & 129299 & 1019 & 196 & 18 & 0.00014 \\
\hline 1988 & 133274 & 967 & 143 & 25 & 0.00019 \\
\hline
\end{tabular}

^From annual reports of General Medical Council. Data are not complete for all years.

†Include disciplinary committee and penal affairs committee before 1980 and preliminary proceedings committee and professional conduct committee after 1980. From 1980 some cases previously considered by disciplinary committees were considered by health committee.

$\ddagger$ As percentage of number of doctors registered with General Medical Council.

both the profession and the public that it is the guardian of appropriate professional behaviour." She perhaps goes too far, but Jean Robinson has argued from inside the disciplinary machinery that "At the end of the day... I feel that we merely become the instrument for the occasional ritual sacrifice." Some other lay members of the council do not agree.

Rosenthal has also produced data on the number of doctors erased from the register as a proportion of all the doctors in Britain: it is tiny and, she says, has declined fairly consistently from $0.0002 \%$ in 1973 to $0.00008 \%$ in $1980 .^{2}$ These figures do not correlate with those I have extracted from the council's annual reports (table $)^{+10}$; the discrepancies may well arise from using different denominators for the number of doctors. I have used the number registered with the council (which is much higher than the number of doctors actually practising), but Rosenthal may be using manpower figures from the Department of Health. Analysis of the council's figures supports her statement that the proportion of doctors erased or suspended is tiny but not her assertion that it is declining.

What is perhaps more interesting is the fact that the number of complaints received by the council is so static whereas the numbers received by defence societies and regional health authorities have increased so rapidly (see fig 3); claims received by the Medical Protection Society increased from about 1000 in 1983 to about 2000 in $1987 .{ }^{11}$ It is hard to know what this means. Why should the GMC not experience the increase in complaints that have been experienced by most other bodies?

\section{Conclusion}

There is unhappiness - both public and professional - with the GMC's disciplinary machinery. Whether the council deals adequately with wicked doctors is questionable, but much more questionable is whether it copes with incompetent doctors. The next article will consider this question as well as examining the mechanisms for dealing with sick doctors.

\footnotetext{
Robinson J. A patient voice at the GMC. A lay member's view of the General Medical Council. London: Health Rights, 1988.

Rosenthal MM. Dealing with medical malpractice: the British and Swedish experience. London: Tavistock, 1987.

3 Committee of Inquiry into the Regulation of the Medical Profession. Report London: HMSO, 1975. (Cmnd 6018.) (Merrison report.)

+ General Medical Council. Annual report 1988. London: GMC, 1989.

5 General Medical Council. Annual report 1973. London: GMC, 1974. 6 General Medical Council. Annual report 1975. London: GMC, 1976. 7 General Medical Council. Annual report 1980. London: GMC, 1981. 8 General Medical Council. Annual report 1985. London: GMC, 1986. 9 General Medical Council. Annual report 1986. London: GMC, 1987. 10 General Medical Council. Annual report 1987. London: GMC, 1988.

11 Ham D, Dingwall R, Fenn P, Harris D. Medical negligence: compensation and
} accountability. London: King's Fund Institute, 1988. 